\title{
A typical red neck
}

\author{
Diego Fernández-Nieto, \\ Darío de Perosanz-Lobo, \\ Juan Jiménez-Cauhé, \\ Daniel Ortega-Quijano, \\ Sonia Bea-Ardebol \\ CASE
}

\begin{abstract}
A woman, aged 46 years, with no notable medical history presented with a one-year history of skin lesions on the upper chest and neck. Occasional itching and burning sensation were noted, with worsening after sun exposure. The patient, who had Fitzpatrick skin type III, had a history of chronic sun exposure and mild solar burns, with only occasional sunscreen protection. She was not taking any prescription medication and did not use fragrances or other topical products. Physical examination revealed erythematous reticular patches with superficial atrophy and occasional hyperpigmentation located in sun-exposed areas of the neck (Figures 1A, 1B).
\end{abstract}

\section{QUESTION 1}

What is the diagnosis?

QUESTION 2

What is the differential diagnosis?

QUESTION 3

What are the treatment options for this disease?

\section{ANSWER 1}

This common condition is poikiloderma of Civatte and presents as a combination of atrophy, telangiectasia, hyperpigmentation and/ or hypopigmentation. It typically appears on the sides of the neck and the anterior upper chest after years of repeated sun exposure. ${ }^{1}$ It has an estimated prevalence of $1.4 \%$, occurring in approximately the fifth decade of life, and is more common in women. ${ }^{2}$ However, prevalence is likely to be higher in countries with populations of light skin phototypes and high sun exposure. $^{2}$

Although the exact causes of poikiloderma of Civatte are unknown, solar radiation is recognised as the primary cause. Hormonal factors, fair skin types and photosensitising components present in some cosmetics are also thought to play a role in the aetiology. ${ }^{3}$ Poikiloderma of Civatte is strongly associated with accumulated photodamage, so it is rarely seen in dark-skinned patients of Fitzpatrick skin type IV or higher. Poikiloderma of Civatte is only a cosmetic concern, with a slowly progressive and irreversible course. Poikiloderma of Civatte is classified into three clinical types: erythemato-telangiectatic, pigmented and mixed, depending on the predominating clinical feature. ${ }^{2}$

\section{ANSWER 2}

The most common conditions to consider in the differential diagnosis are pigmented contact dermatitis (also known as Riehl's melanosis) and erythromelanosis follicularis faciei et colli (EFFC).

Pigmented contact dermatitis occurs as a result of phototoxic or photoallergic reactions. It has been associated with many cosmetic compounds, typically bergamot oil. Spotted brown pigmentation predominates, with minimal or absent telangiectasia and smaller follicular papules. ${ }^{2}$ It also affects dark-skinned patients, and the face is more commonly involved than in poikiloderma of Civatte.

EFFC has been suggested to be a subtype of keratosis pilaris that usually affects young males. It presents as hyperpigmentation, follicular plugging and erythema predominantly affecting the lateral aspects of cheeks and rarely the neck. ${ }^{1}$

Other conditions that should be included in the differential diagnosis are chronic graft versus host disease, friction melanosis, melasma, localised scleroderma, radiation-induced skin changes and poikiloderma vasculare atrophicans (an unusual manifestation of cutaneous T-cell lymphoma). ${ }^{4}$

Rothmund-Thomson syndrome is a genodermatosis characterised by facial poikiloderma in childhood, short stature, premature ageing and predisposition to certain cancers. Bloom syndrome is a chromosomal breakage syndrome characterised by sun-sensitive facial telangiectatic erythema, susceptibility to infections and cancer.

Phototoxic and photoallergic reactions to medication should also be considered, and a thorough anamnesis including present medications and over-thecounter products is recommended.

Photosensitive connective tissue diseases such as dermatomyositis and lupus erythematosus usually present as erythematous macules or plaques predominantly affecting sun-exposed areas, including the neck. Signs and symptoms such as fever, fatigue, weight 
loss, myalgias, arthritis and oral ulcers should be evaluated.

Furthermore, atypical forms of poikiloderma of Civatte should be biopsied and/or referred to a dermatologist.

\section{ANSWER 3}

Sun protection is crucial to stop progression. High sun protection factor sunscreen is recommended, as well as physical barriers such as scarves, collared shirts and hats. Skin cancers should be monitored. Avoidance of perfumes is recommended, and patch testing can be useful if induction by allergen is suspected. ${ }^{5}$

Treatment options include a variety of energy-based therapies. The most common options are intense pulsed light, pulsed dye laser and fractionated ablative and non-ablative lasers. Choice is based on the predominance of telangiectasias, atrophy or pigmentation disorder. Intense pulsed light can improve both dyspigmentation and telangiectasias and reports a $50-75 \%$ improvement with a low side-effect profile. ${ }^{6}$

\section{CASE Continued}

The patient was reassured of the benign nature of her condition. No atypical skin lesions were present, and no further intervention was required.

\section{Key points}

- Poikiloderma of Civatte is a benign condition associated with chronic sun exposure; it typically affects sun-exposed areas of the neck.

- Sun protection and monitoring of skin cancers is recommended.

\section{Authors}

Diego Fernández-Nieto MD, Dermatologist Dermatology Department, Hospital Universitario Ramón y Cajal, Madrid, Spain.

fnietodiego@gmail.com

Darío de Perosanz-Lobo MD, Dermatologist, Dermatology Department, Hospital Universitario Ramón y Cajal, Madrid, Spain

Juan Jiménez-Cauhé MD, Dermatologist,

Dermatology Department, Hospital Universitario Ramón y Cajal, Madrid, Spain

Daniel Ortega-Quijano MD, Dermatologist,

Dermatology Department, Hospital Universitario Ramón y Cajal, Madrid, Spain
Sonia Bea-Ardebol Dermatology Department, Hospital Universitario Ramón y Cajal, Madrid, Spain Competing interests and funding: None.

Provenance and peer review: Not commissioned, externally peer reviewed.

\section{References}

1. Griffiths CEM, Barker J, Chalmers R, Bleiker T, Chalmers R, Creamer D. Rook's Textbook of Dermatology. 9th edn. New York, USA: John Wiley \& Sons, 2016.

2. Katoulis AC, Stavrianeas NG, Georgala S, et al. Poikiloderma of Civatte: A clinical and epidemiological study. J Eur Acad Dermatol Venereol 2005;19(4):444-48. doi: 10.1111/j.14683083.2005.01213.x

3. Nofal A, Salah E. Acquired poikiloderma: Proposed classification and diagnostic approach. J Am Acad Dermatol 2013;69(3):e129-40. doi: 10.1016/j. jaad.2012.06.015

4. Lautenschlager S, Itin PH. Reticulate, patchy and mottled pigmentation of the neck. Acquired forms. Dermatology 1998;197(3):291-96. doi: 10.1159/000018016.

5. Katoulis AC, Stavrianeas NG, Katsarou A, et al. Evaluation of the role of contact sensitization and photosensitivity in the pathogenesis of poikiloderma of Civatte. Br J Dermatol 2002;147(3):493-97. doi: 10.1046/j.13652133.2002.04993.x.

6. Goldman MP, Weiss RA. Treatment of poikiloderma of Civatte on the neck with an intense pulsed light source. Plast Reconstr Surg 2001;107(6):1376-381. doi: 10.1097/00006534200105000-00009.

correspondence ajgp@racgp.org.au
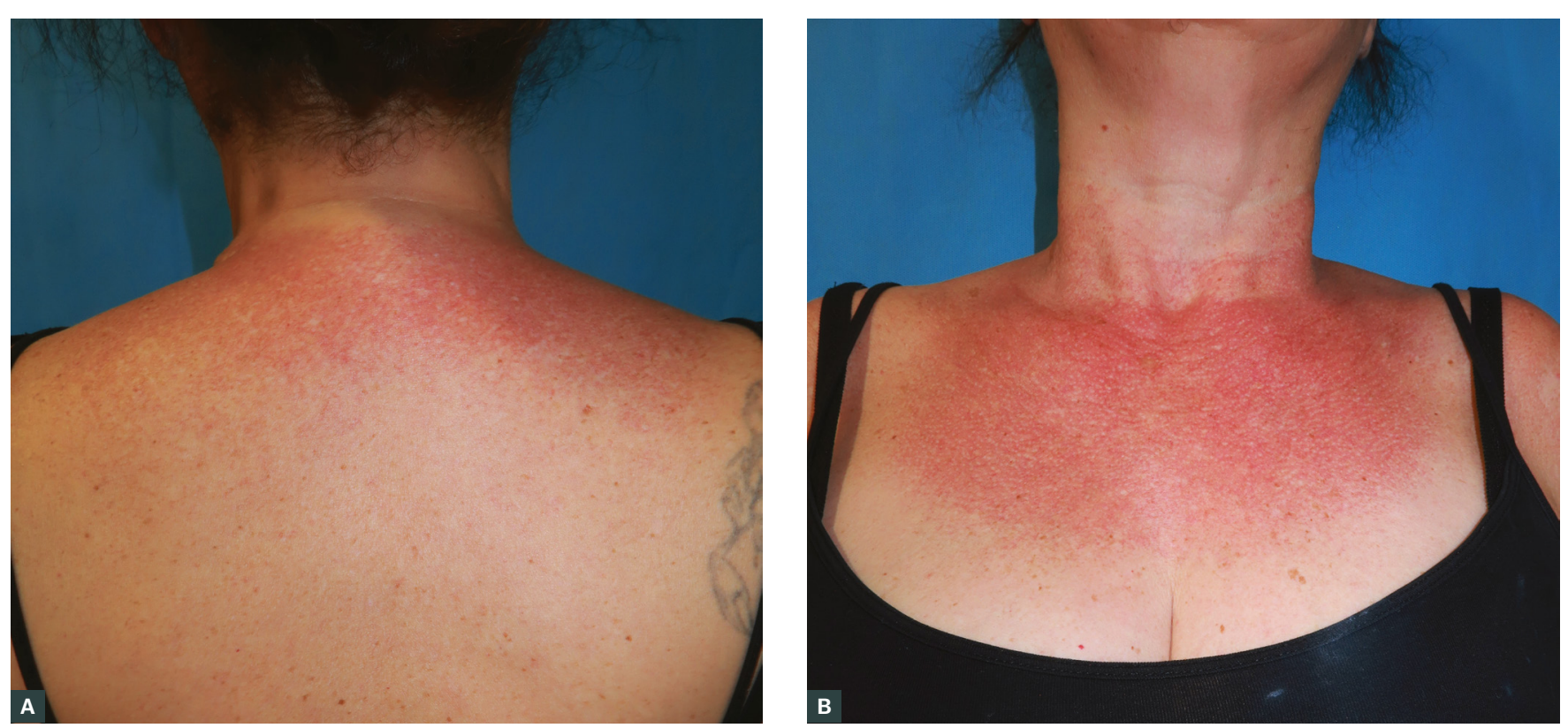

Figure 1. Clinical presentation of the patient

A. Erythematous reticular patches with telangiectasias and prominent hair follicles located at the upper back; B. Same clinical findings in the upper chest and neck; sparing of the submental area is present 